\title{
Physiological and clinical relevance of exercise ventilatory efficiency in COPD
}

\author{
J. Alberto Neder ${ }^{1}$, Danilo C. Berton ${ }^{1,2}$, Flavio F. Arbex ${ }^{3}$, Maria Clara Alencar ${ }^{4}$, \\ Alcides Rocha ${ }^{3}$, Priscila A. Sperandio ${ }^{3}$, Paolo Palange ${ }^{5}$ and Denis E. O'Donnell
}

Affiliations: ${ }^{1}$ Respiratory Investigation Unit and Laboratory of Clinical Exercise Physiology, Queen's University and Kingston General Hospital, Kingston, ON, Canada. ${ }^{2}$ Division of Respiratory Medicine, Federal University of Rio Grande do Sul, Porto Alegre, Brazil. ${ }^{3}$ Pulmonary Function and Clinical Exercise Physiology, Respiratory Division, Federal University of Sao Paulo, Sao Paulo, Brazil. ${ }^{4}$ Division of Cardiology, Federal University of Minas Gerais, Belo Horizonte, Brazil. ${ }^{5}$ Dept of Public Health and Infectious Diseases, Sapienza University of Rome, Rome, Italy.

Correspondence: J. Alberto Neder, 102 Stuart Street, Kingston, Ontario, Canada K7L 2V6.

E-mail: alberto.nederवqueensu.ca

@ERSpublications

Ventilatory efficiency is a key measurement for the interpretation of cardiopulmonary exercise testing in COPD http://ow.ly/1nsY307pbz8

Cite this article as: Neder JA, Berton DC, Arbex FF, et al. Physiological and clinical relevance of exercise ventilatory efficiency in COPD. Eur Respir J 2017; 49: 1602036 [https://doi.org/10.1183/13993003.020362016].

ABSTRACT Exercise ventilation $\left(V^{\prime} \mathrm{E}\right)$ relative to carbon dioxide output $\left(V^{\prime} \mathrm{CO}_{2}\right)$ is particularly relevant to patients limited by the respiratory system, e.g. those with chronic obstructive pulmonary disease (COPD). High $V^{\prime} \mathrm{E}-V^{\prime} \mathrm{CO}_{2}$ (poor ventilatory efficiency) has been found to be a key physiological abnormality in symptomatic patients with largely preserved forced expiratory volume in $1 \mathrm{~s}$ (FEV1). Establishing an association between high $V^{\prime} \mathrm{E}-V^{\prime} \mathrm{CO}_{2}$ and exertional dyspnoea in mild COPD provides evidence that exercise intolerance is not a mere consequence of detraining. As the disease evolves, poor ventilatory efficiency might help explaining "out-of-proportion" breathlessness (to FEV1 impairment). Regardless, disease severity, cardiocirculatory co-morbidities such as heart failure and pulmonary hypertension have been found to increase $V^{\prime} \mathrm{E}-V^{\prime} \mathrm{CO}_{2}$. In fact, a high $V^{\prime} \mathrm{E}-V^{\prime} \mathrm{CO}_{2}$ has been found to be a powerful predictor of poor outcome in lung resection surgery. Moreover, a high $V^{\prime} \mathrm{E}-V^{\prime} \mathrm{CO}_{2}$ has added value to resting lung hyperinflation in predicting all-cause and respiratory mortality across the spectrum of COPD severity. Documenting improved ventilatory efficiency after lung transplantation and lung volume reduction surgery provides objective evidence of treatment efficacy. Considering the usefulness of exercise ventilatory efficiency in different clinical scenarios, the $V^{\prime} \mathrm{E}-V^{\prime} \mathrm{CO}_{2}$ relationship should be valued in the interpretation of cardiopulmonary exercise tests in patients with mild-to-end-stage COPD.

This article has supplementary material available from erj.ersjournals.com

Received: Oct 172016 | Accepted after revision: Dec 122016

Support statement: J.A. Neder has been funded by a New Clinician Scientist Program from the Southeastern Ontario Academic Medical Association (SEAMO), Canada. The funder had no role in the study design, data collection and analysis, or preparation of the manuscript.

Conflict of interest: None declared.

Copyright @ERS 2017 
To me it does not seem all movements are exercise, but only when it is vigorous. Since vigor is relative, the same movement might be exercise for one and not for another. The criterion of vigorousness is change of respiration; those movements which do not alter the respiration are not exercise.

Galen, Exercise and Massage, in On Hygiene, circa 200 AD

\section{Introduction}

Dynamic exercise, as recognised by Galen, is characteristically associated with changes in frequency and depth of breathing, i.e. hyperpnoea. Moreover, he cogently observed that those respiratory changes are somehow linked to exercise intensity ("movement vigorousness"). Eighteen centuries later we now know that changes in exercise pulmonary ventilation $\left(V^{\prime} E\right)$, at least before the development of metabolic acidosis (or hypoxaemia in disease), are exquisitely commensurate to the rate at which metabolically produced carbon dioxide is released by the lungs $\left(V^{\prime} \mathrm{CO}_{2}\right.$, i.e. venous return $\times$ mixed-venous $\mathrm{CO}_{2}$ content) $[1,2]$. Thus, the response of $V^{\prime} \mathrm{E}$ relative to $V^{\prime} \mathrm{CO}_{2}$ (the $V^{\prime} \mathrm{E}-V^{\prime} \mathrm{CO}_{2}$ relationship) has been named "ventilatory efficiency" [3], an implicit recognition that meeting metabolic demand to maintain arterial blood gas and $\mathrm{pH}$ is the overriding goal of ventilation [2]. Although increased (or even decreased) $V^{\prime} \mathrm{E}$ relative to $V^{\prime} \mathrm{CO}_{2}$ may not always inform us how efficient $V^{\prime} \mathrm{E}$ is relative to arterial blood gas homeostasis (see section Physiological bases), the term "ventilatory efficiency" has gained popularity to describe the exercise $V^{\prime} \mathrm{E}-V^{\prime} \mathrm{CO}_{2}$ relationship [4-7].

It is rather axiomatic that the issue of exercise ventilatory efficiency is particularly relevant to patients primarily limited by ventilation, e.g. those with chronic obstructive pulmonary disease (COPD) [8, 9]. Surprisingly, however, its clinical importance has been mostly recognised in diseases for which mechanicalventilatory constraints are not the dominant feature, e.g. heart failure [4-7, 10] and pulmonary arterial hypertension $(\mathrm{PAH})[11,12]$. More recently, however, a substantial body of evidence has accumulated showing that abnormalities in the $V^{\prime} \mathrm{E}-V^{\prime} \mathrm{CO}_{2}$ relationship during incremental cardiopulmonary exercise testing (CPET) are present across the spectrum of COPD severity. Thus, $V^{\prime} \mathrm{E}-V^{\prime} \mathrm{CO}_{2}$ measurement has advanced our understanding of mechanisms of exercise intolerance and, particularly in milder COPD, exertional breathlessness. Moreover, this measurement has allowed us to better judge the functional impact of co-morbidities, to assess future risk and prognosis and to determine the complex effects of therapeutic interventions on exercise tolerance in COPD (table 1). The present manuscript will discuss these emerging findings from a clinically applied perspective with emphasis on the extant gaps in current knowledge.

\section{Physiological bases}

It is well established that the $V^{\prime} \mathrm{E}$ required to washout a given rate of $\mathrm{CO}_{2}$ production is higher the lower the arterial partial pressure for $\mathrm{CO}_{2}\left(\mathrm{aCO}_{2}\right)$ (as more $V^{\prime} \mathrm{E}$ is needed to keep $\mathrm{PaCO}_{2}$ low compared with a high value) and the larger the ventilation "wasted" in the dead space (VD), i.e.

$$
\frac{V_{\mathrm{E}}^{\prime}}{V_{\mathrm{CO}_{2}}^{\prime}}=\frac{1}{P_{\mathrm{aCO}_{2}} \times\left(1-\left(\frac{V_{\mathrm{D}}}{V_{\mathrm{T}}}\right)\right)}
$$

where $V^{\prime} \mathrm{E} / V^{\prime} \mathrm{CO}_{2}$ ratio is the ventilatory equivalent for $\mathrm{CO}_{2}$ and $V \mathrm{D} / V \mathrm{~T}$ is the physiological (anatomical plus alveolar) dead space fraction of tidal volume [2]. Of note, $V \mathrm{D} / V \mathrm{~T}$ decreases in a curvilinear manner as exercise progresses, i.e. more alveoli are recruited as $V \mathrm{~T}$ and $V^{\prime} \mathrm{E}$ increase (figure 1a) [67]. Thus, a major contribution to the decreasing $V \mathrm{D} / V \mathrm{~T}$ is the greater compliance of the alveoli over that of the airways, allowing greater alveoli expansion relative to the airways ([67] and reviewed in [68]). Moreover, VT increases owing to a large increase in end-inspiratory lung volume and a small, but important, decrease in end-expiratory lung volume; thus, VT remains positioned on the most compliant (linear) portion of the respiratory system S-shaped pressure-volume relationship (as reviewed in [69]).

In this context, if $V^{\prime} \mathrm{E} / V^{\prime} \mathrm{CO}_{2}$ did not decrease in tandem with $V \mathrm{D} / V_{\mathrm{T}}$ the resulting alveolar hyperventilation would lower $\mathrm{PaCO}_{2}$ leading to progressive respiratory alkalosis [2, 70]. Although the exact mechanisms remain controversial (see [71] and [72] for a recent debate on the topic), $V^{\prime} \mathrm{E} / V^{\prime} \mathrm{CO}_{2}$ decreases in direct proportion to $V \mathrm{D} / V_{\mathrm{T}}$ (figure 1b). Thus, $\mathrm{PaCO}_{2}$ is kept constant $(\leftrightarrow)$ during mild-to-moderate exercise in healthy humans (figure 1c) $[1,2,67,73]$ :

$$
\leftrightarrow P_{\mathrm{aCO}_{2}}=\frac{1}{\downarrow \frac{V_{\mathrm{E}}^{\prime}}{V_{\mathrm{CO}_{2}}^{\prime}} \times\left(1-\left(\frac{\downarrow V_{\mathrm{D}}}{\uparrow V_{\mathrm{T}}}\right)\right)}
$$


TABLE 1 Overview of cardiopulmonary exercise testing-based studies on ventilatory efficiency in different clinical scenarios in chronic obstructive pulmonary disease (COPD)

\begin{tabular}{|c|c|c|}
\hline Clinical context & Subjects $n$ & Disease severity \\
\hline \multicolumn{3}{|c|}{ Exercise intolerance } \\
\hline Palange [13] & 9 & $\mathrm{FEV}_{1}<50 \%$ \\
\hline O'DonNeLL [14] & 20 & $\mathrm{FEV}_{1}=34 \pm 3 \%$ \\
\hline NaKaмото [15] & 10 & $\mathrm{FEV}_{1}=27-70 \%$ \\
\hline OFIR [16] & 42 & $\mathrm{FEV} 1=91 \pm 8 \%$ \\
\hline ORA [17] & 36 & $F E V_{1}=49 \pm 10 \%$ \\
\hline Paoletti [18] & 16 & $\mathrm{FEV}_{1}=54 \pm 18 \%$ \\
\hline GuenetTe [19] & 64 & $F E V_{1}=86 \pm 11 \%$ \\
\hline Caviedes [20] & 35 & $F E V_{1}=59 \pm 22 \%$ \\
\hline CHIN [21] & 40 & $F E V_{1}=87 \pm 11 \%$ \\
\hline TEOPOMPI [22] & 56 & $F E V_{1}=26-80 \%$ \\
\hline GuenETTE [23] & 32 & $F E V_{1}=93 \pm 9 \%$ \\
\hline CIAVAGLIA [24] & 12 & $F E V_{1}=60 \pm 13 \%$ \\
\hline BARRON [25] & 24 & $F E V_{1}=60 \pm 13 \%$ \\
\hline
\end{tabular}

O'Donnell [26]

Neder [27]

ELBEHAIRY [28]

Neder [29]

ELBEHAIRY [30]

FAISAL [31]

Crisafulli [32]

ELBEHAIRY [33]

SOUMAGNE [34]

JoNES [35]

\section{Influence of co-morbidities}

HoLvERDA [36]

VonBank [37]

BoERRIGTER [38]

ThiRAPATARATONG [39]

Thirapataratong [40]

Teopompl [41]

ThirapataRATONg [42]

Apostolo [43]

ARBEX [44]

Rocha [45]

Risk assessment/prognosis

TORCHIO [46]

BRUNeLLI [47]

SHAFIEK [48]

Neder [49]

Alencar [50]

Effects of interventions

ORENS [51]

SOMFAY [52]

O'Donnell [53]

O'DonNell [54]
GOLD 1 and 2 GOLD 1 to 4 $\mathrm{FEV} 1=91 \pm 10 \%$ GOLD 1 to 4

$\mathrm{FEV}_{1}=94 \pm 10 \%$ $F E V 1=63 \pm 22 \%$

$\mathrm{FEV}_{1}=55 \pm 16 \%$ $\mathrm{FEV}_{1}=101 \pm 13 \%$ $F E V_{1}=-1.02 \pm 0.64$ z-score $F E V_{1}=82 \pm 13 \%$

NA

$F E V_{1}=1.1 \pm 0.5 \mathrm{~L}$ $F E V_{1}=55 \pm 17 \%$ $\mathrm{FEV}_{1}=31 \pm 10 \%$ $\mathrm{FEV}_{1}=20 \pm 7 \%$

$\mathrm{FEV}_{1}=52 \pm 16 \%$

$F E V_{1}=26 \pm 14 \%$ $\mathrm{FEV}_{1}=53 \pm 13 \%$

$\mathrm{FEV}_{1}=55 \pm 17 \%$

$\mathrm{FEV}_{1}=60 \pm 18 \%$

$\mathrm{FEV}_{1}=73 \pm 16 \%$ $\mathrm{FEV}_{1}=81 \pm 18 \%$

$\mathrm{FEV}_{1}=60 \pm 17 \%$

$\mathrm{FEV} 1=18-148 \%$ $\mathrm{FEV} 1=57 \pm 17 \%$

$\mathrm{FEV}_{1}=57 \pm 4 \%$

$\mathrm{FEV}_{1}=31 \pm 10 \%$

$\mathrm{FEV} 1=31 \pm 3 \%$

$\mathrm{FEV} 1=42 \pm 3 \%$ $\uparrow V^{\prime} \mathrm{E}-V^{\prime} \mathrm{CO}_{2}$ slope in walking than cycling

$\downarrow V^{\prime} E$ at a given $V^{\prime} \mathrm{CO}_{2}$ in $\mathrm{CO}_{2}$ retainers compared with non-retainers $V^{\prime} \mathrm{E}-V^{\prime} \mathrm{CO}_{2}$ slope not related to increased muscle ergoreflex activity $\uparrow V^{\prime} E / V^{\prime} \mathrm{CO}_{2}$ nadir in mild COPD with chronic dyspnoea $\downarrow V^{\prime} \mathrm{E} / \mathrm{V}^{\prime} \mathrm{CO}_{2}$ nadir in obese patients with COPD

$\downarrow V^{\prime} \mathrm{E}-V^{\prime} \mathrm{CO}_{2}$ slope in more extensive emphysema No sex effect on $V^{\prime} E / V^{\prime} \mathrm{CO}_{2}$ nadir

$\uparrow V^{\prime} \mathrm{E} / \mathrm{V}^{\prime} \mathrm{CO}_{2}$ nadir associated with lower maximal exercise capacity $\uparrow V^{\prime} E / V^{\prime} \mathrm{CO}_{2}$ with added external dead space in mild COPD

$\uparrow V^{\prime} \mathrm{E}-V^{\prime} \mathrm{CO}_{2}$ intercept related to greater dynamic hyperinflation $\uparrow V^{\prime} \mathrm{E}-V^{\prime} \mathrm{CO}_{2}$ slope associated with lower maximal exercise capacity $\uparrow V^{\prime} \mathrm{E} / V^{\prime} \mathrm{CO}_{2}$ throughout incremental exercise in mild COPD No effect of exercise modality on $V^{\prime} E / V^{\prime} \mathrm{CO}_{2}$ in obese patients with COPD $V^{\prime} E / V^{\prime} \mathrm{CO}_{2}$ nadir showed excellent test-retest reliability superior to $V^{\prime} \mathrm{E}-V^{\prime} \mathrm{CO}_{2}$ slope

$V^{\prime} \mathrm{E} / V^{\prime} \mathrm{CO}_{2}$ nadir showed better test-retest reliability in COPD than heart failure

$\uparrow V^{\prime} \mathrm{E} / \mathrm{V}^{\prime} \mathrm{CO}_{2}$ throughout incremental treadmill tests in GOLD 1 and 2 $\uparrow V^{\prime} E-V^{\prime} \mathrm{CO}_{2}$ slope associated with ventilation inhomogeneity in GOLD 1 and 2 $\uparrow V^{\prime} \mathrm{E} / V^{\prime} \mathrm{CO}_{2}$ nadir in GOLD grade $1 \mathrm{~B}$ with and without chronic bronchitis $\uparrow V^{\prime} \mathrm{E}-V^{\prime} \mathrm{CO}_{2}$ intercept from GOLD 1 to 4 associated with exertional dyspnoea $\uparrow V^{\prime} \mathrm{E}-V^{\prime} \mathrm{CO}_{2}$ slope in GOLD 1 and 2 but lower slopes in GOLD 3 and 4 $\uparrow V^{\prime} E / V^{\prime} \mathrm{CO}_{2}$ associated with greater $V_{\mathrm{D}} / V_{\mathrm{T}}$ in symptomatic GOLD 1

$\uparrow V^{\prime} E / V^{\prime} \mathrm{CO}_{2}$ in COPD and ILD presenting with similar resting inspiratory capacity

$\uparrow V^{\prime} E / V^{\prime} \mathrm{CO}_{2}$ slope associated with emphysema extension on chest CT Similar $V^{\prime} E / V^{\prime} \mathrm{CO}_{2}$ in smokers without COPD and healthy controls

$\uparrow V^{\prime} E / V^{\prime} \mathrm{CO}_{2}$ nadir in asymptomatic smokers with airflow obstruction

$\uparrow V^{\prime} \mathrm{E} / V^{\prime} \mathrm{CO}_{2}$ nadir associated with emphysema extension and lower transfer factor

$\uparrow V^{\prime} E / V^{\prime} \mathrm{CO}_{2}$ nadir associated with mean pulmonary artery pressure $\uparrow$ Rest and peak $V^{\prime} E / V^{\prime} \mathrm{CO}_{2}$ in patients with associated $\mathrm{PAH}$

Pronounced $\uparrow V^{\prime} \mathrm{E}-V^{\prime} \mathrm{CO}_{2}$ slope in a sub-group (n=9) with severe PAH No effect of $\beta$-blockers on $V^{\prime} E / V^{\prime} \mathrm{CO}_{2}$ nadir

No association of peak $V^{\prime} E / V^{\prime} \mathrm{CO}_{2}$ with PAH in severe to very severe COPD

$\downarrow V^{\prime} E-V^{\prime} \mathrm{CO}_{2}$ slope in COPD compared with heart failure in patients with poorer exercise capacity

$\uparrow V^{\prime} \mathrm{E}-V^{\prime} \mathrm{CO}_{2}$ intercept in COPD compared with heart failure $\uparrow V^{\prime} E / V^{\prime} \mathrm{CO}_{2}$ nadir in COPD patients with coexistent coronary artery disease $\uparrow V^{\prime} E-V^{\prime} \mathrm{CO}_{2}$ intercept in COPD and COPD- heart failure compared with heart failure

$\uparrow V^{\prime} E-V^{\prime} \mathrm{CO}_{2}$ slope and $V^{\prime} \mathrm{E} / V^{\prime} \mathrm{CO}_{2}$ nadir in COPD- heart failure compared with COPD

$\checkmark V^{\prime} \mathrm{E}-V^{\prime} \mathrm{CO}_{2}$ intercept in COPD- heart failure compared with COPD $\uparrow V^{\prime} \mathrm{E}-V^{\prime} \mathrm{CO}_{2}$ slope in COPD- heart failure with exercise oscillatory ventilation

$V^{\prime} \mathrm{E}-V^{\prime} \mathrm{CO}_{2}$ slope $\geqslant 34$ predicted mortality after lung resection surgery $V^{\prime} E-V^{\prime} \mathrm{CO}_{2}$ slope $\geqslant 35$ predicted poor outcome after lung resection surgery

$V^{\prime} E-V^{\prime} \mathrm{CO}_{2}$ slope $>35$ predicted poor outcome after lung resection surgery

$V^{\prime} E / V^{\prime} \mathrm{CO}_{2}$ nadir $>34$ added to resting hyperinflation to predict mortality $V^{\prime} \mathrm{E} / V^{\prime} \mathrm{CO}_{2}$ nadir $>34$ and right ventricular function predicted mortality in COPD-heart failure

Single lung transplant decreased $V^{\prime} \mathrm{E} / V^{\prime} \mathrm{CO}_{2}$ peak Decrements in $V^{\prime} E$ with hyperoxia correlated with decreases in $V^{\prime} \mathrm{CO}_{2}$ Proportional decrements $V^{\prime} \mathrm{E}$ and $V^{\prime} \mathrm{CO}_{2}$ with hyperoxia in advanced $\mathrm{COPD}$ Salmeterol proportionally increased $V^{\prime} E$ and $V^{\prime} \mathrm{CO}_{2}$ during constant work rate exercise 
TABLE 1 Continued

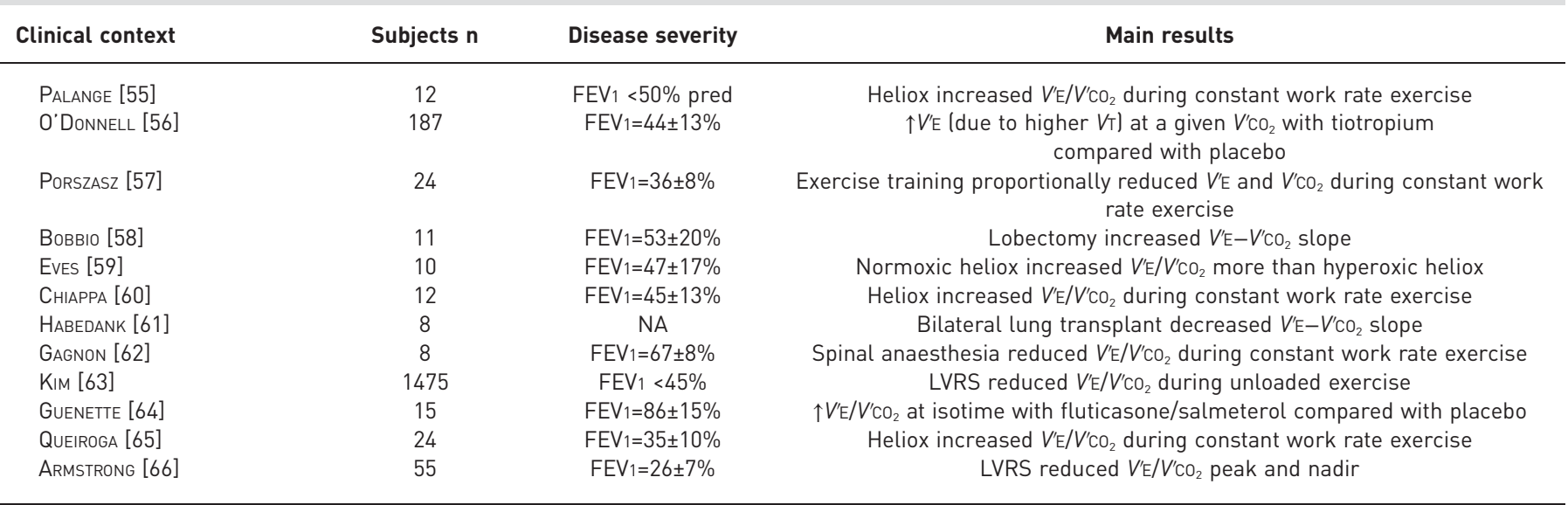

$\uparrow$ : increased; $\downarrow$ : decreased; FEV1: forced expiratory volume in one second; $V^{\prime} E$ : ventilation; $V^{\prime} \mathrm{CO}_{2}$ : carbon dioxide output; PAH: pulmonary arterial hypertension; GOLD: Global Initiative for Obstructive Lung Disease; ILD: interstitial lung disease; LVRS: lung volume reduction surgery; NA: not available.

These considerations provide the physiological basis for the assertion that the $V^{\prime} \mathrm{E} / V^{\prime} \mathrm{CO}_{2}$ profile provides useful information about the $V \mathrm{D} / V \mathrm{~T}$ trajectory, particularly if $\mathrm{PaCO}_{2}$ is concomitantly measured $[2,67,70,74]$. The major assumptions, however, are the absence of mechanical constraints to $V^{\prime} \mathrm{E}$ increase [75], i.e. the "output" $\left(V^{\prime} \mathrm{E}\right)$ can appropriately adjust to its determinants $\left(V^{\prime} \mathrm{CO}_{2}, V \mathrm{D} / V \mathrm{~T}\right.$ and $\left.\mathrm{PaCO}_{2}\right)$ and there is neither exercise-induced hypercapnia nor increased additional chemo-stimulation of ventilation, e.g. hypoxaemia $[1,2,4,73]$.

Equation 1 also helps us to understand why increases in $V^{\prime} E$ relative to $V^{\prime} \mathrm{CO}_{2}$ do not necessarily imply poor ventilatory efficiency. For instance, the system is arguably not "inefficient" if a high $V^{\prime} \mathrm{E} / V^{\prime} \mathrm{CO}_{2}$ is needed to keep $\mathrm{PaCO}_{2}$ at a low level as determined by the respiratory controller (e.g. chronic respiratory alkalosis or chronic metabolic acidosis) or there is an extra source of afferent stimuli to increase ventilation (e.g. hypoxaemia) [10]. For the sake of simplicity, the subsequent discussion assumes that an increased slope of the $V^{\prime} \mathrm{E}-V^{\prime} \mathrm{CO}_{2}$ relationship and/or an increased $V^{\prime} E / V^{\prime} \mathrm{CO}_{2}$ ratio equals "poor efficiency" unless otherwise specified.

\section{Methodological considerations}

In response to rapidly incremental CPET, the $V^{\prime} \mathrm{E}-V^{\prime} \mathrm{CO}_{2}$ relationship has been analysed in the $V^{\prime} \mathrm{E} / V^{\prime} \mathrm{CO}_{2}$ ratio versus $V^{\prime} \mathrm{CO}_{2}$ plot (figure $1 \mathrm{~b}$ ) or in the $V^{\prime} \mathrm{E}$ versus $V^{\prime} \mathrm{CO}_{2}$ plot (figure 1d) [4]. The lowest (nadir) $V^{\prime} \mathrm{E} / V^{\prime} \mathrm{CO}_{2}$ is typically reached just before $V^{\prime} \mathrm{E}$ starts to increase in compensation for lactic acidosis at the respiratory compensation point (RCP) (figure $1 \mathrm{~b}-\mathrm{d}$ ). Provided the subject can tolerate high levels of exercise (i.e. high $V^{\prime} \mathrm{CO}_{2}$ ), $V^{\prime} \mathrm{E} / V^{\prime} \mathrm{CO}_{2}$ virtually equals (i.e. "asymptotes") to the slope of the $V^{\prime} \mathrm{E}-V^{\prime} \mathrm{CO}_{2}$ relationship (refer to the supplementary material for further elaboration) [76]. Thus, the $V^{\prime} \mathrm{E} / V^{\prime} \mathrm{CO}_{2}$ nadir and $V^{\prime} \mathrm{E} / V^{\prime} \mathrm{CO}_{2}$ at the lactate threshold are almost indistinguishable in normal subjects [74]. As the lactate threshold may not always be identified, particularly in clinical populations with low exercise capacity [77, 78], the $V^{\prime} \mathrm{E} / V^{\prime} \mathrm{CO}_{2}$ nadir seems a more accurate indication of ventilatory efficiency than the $V^{\prime} \mathrm{E} / V^{\prime} \mathrm{CO}_{2}$ at the lactate threshold. The $V^{\prime} \mathrm{E} / V^{\prime} \mathrm{CO}_{2}$ nadir has been found to be highly reproducible in normal subjects [74] and in patients with COPD [25]. The $V^{\prime} \mathrm{E} / V^{\prime} \mathrm{CO}_{2}$ nadir, however, might underestimate ventilatory efficiency if the $V^{\prime} \mathrm{E} / V^{\prime} \mathrm{CO}_{2}$ descending curve is prematurely interrupted (dashed line in figure 1b), e.g. premature lactic acidosis or an excessively short test duration [79]. As expected, end-exercise $V^{\prime} \mathrm{E} / V^{\prime} \mathrm{CO}_{2}$ is higher than the nadir as the former incorporates the hyperventilatory response to late-exercise acidosis. In other words, end-exercise $V^{\prime} \mathrm{E} / V^{\prime} \mathrm{CO}_{2}$, by definition, does not constitute an index of ventilatory efficiency in those who are able to exercise beyond the RCP. Most patients with moderate-to-severe COPD, however, either do not reach the $\mathrm{RCP}$ or are unable to further increase $V^{\prime} \mathrm{E}$. Thus, nadir and end-exercise $V^{\prime} \mathrm{E} / V^{\prime} \mathrm{CO}_{2}$ are often equivalent in most patients, with the exception of some less impaired patients with milder disease [29].

It is important to recognize that the $V^{\prime} \mathrm{E} / V^{\prime} \mathrm{CO}_{2}$ response contour is intrinsically linked to how $V^{\prime} \mathrm{E}$ dynamically changes in relation to $V^{\prime} \mathrm{CO}_{2}$ taking into consideration its starting point $[2,4,71,72,76]$. The former is reflected by the slope of the regression line between $V^{\prime} \mathrm{E}$ and $V^{\prime} \mathrm{CO}_{2}$ and the latter by its intercept (i.e. $V^{\prime} \mathrm{E}$ when $V^{\prime} \mathrm{CO}_{2}=0$ ) (figure 1 and figure $\mathrm{S} 1$ ). Considering that in normal subjects the $V^{\prime} \mathrm{E}$ intercept is often a small positive number ( $<3 \mathrm{~L} \mathrm{~min}{ }^{-1}$ on average) [74], $V^{\prime} \mathrm{E} / V^{\prime} \mathrm{CO}_{2}$ equals the slope of the $V^{\prime} \mathrm{E}-V^{\prime} \mathrm{CO}_{2}$ relationship at high $V^{\prime} \mathrm{CO}_{2}$ values (refer to the supplementary material for further elaboration) $[67,70,76]$. It should be noted 

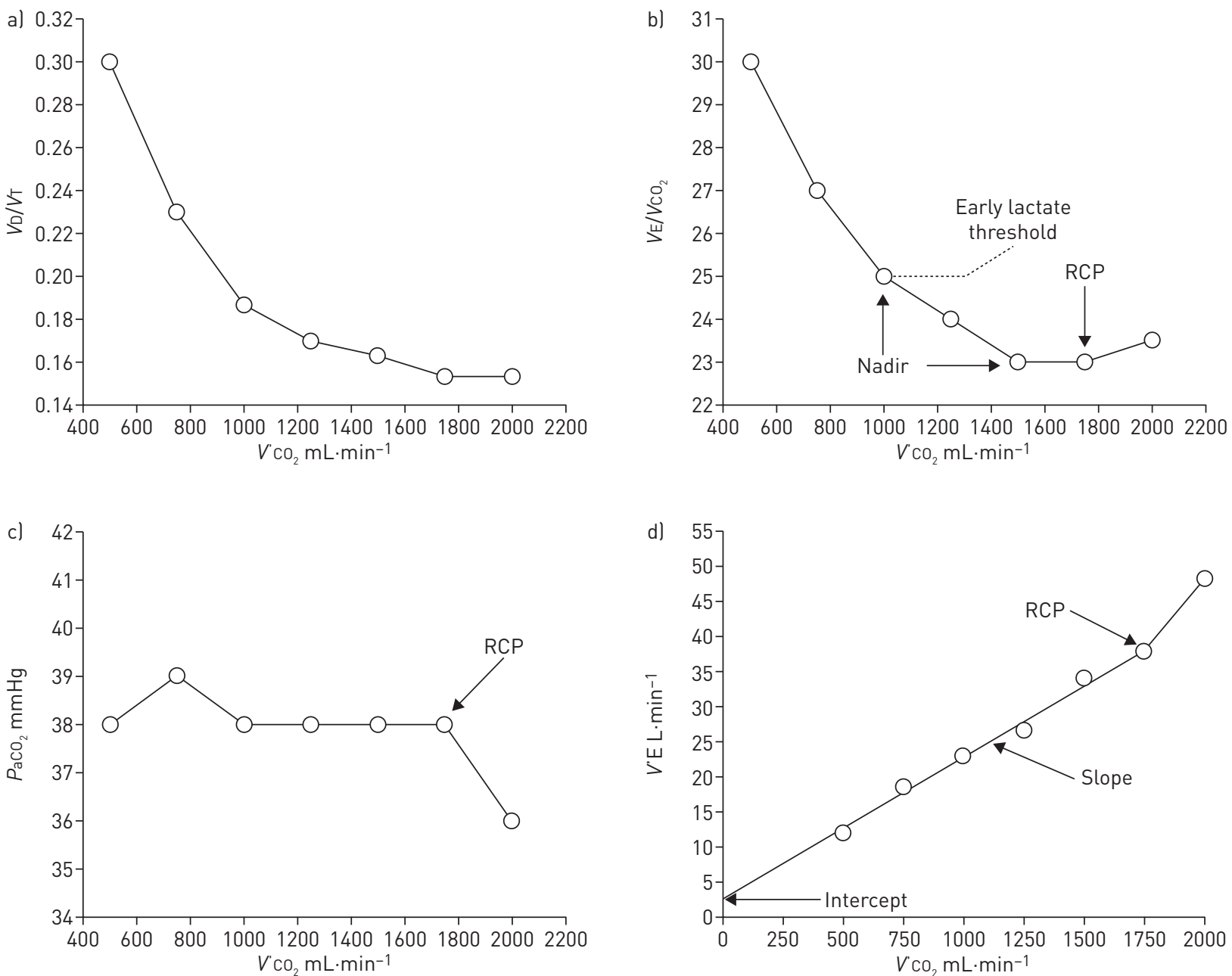

FIGURE 1 Selected ventilatory and gas exchange responses to incremental CPET in a young healthy male. Proportional decreases in dead space $\left(V_{D}\right) /$ tidal volume $\left(V_{T}\right)(a)$ and ventilation $\left(V^{\prime} E\right) /$ carbon dioxide output $\left(V^{\prime} \mathrm{CO}_{2}\right)$ (b) ratios maintain arterial carbon dioxide partial pressure $\left(P_{a}\right.$ aco $)$ close to resting value during mild-to-moderate exercise (c). The $V^{\prime} E / V^{\prime} \mathrm{CO}_{2}$ response contour is established by both slope and intercept of the linear $V^{\prime} \mathrm{E}-V$ ${ }^{\prime} \mathrm{CO}_{2}$ relationship (d). Thus, the lowest (nadir) $V^{\prime} E / V^{\prime} \mathrm{CO}_{2}$ closely approximates slope plus intercept. $V^{\prime} E-V^{\prime} \mathrm{CO}_{2}$ increases out of proportion to $V^{\prime} \mathrm{CO}_{2}$ after the respiratory compensation point (RCP) (b-d) leading to respiratory alkalosis (c) to compensate for progressive lactacidaemia. Note the increases in nadir when the lactate threshold is reached earlier (dashed line in b).

that considering all data points (i.e. including those after the RCP) will necessarily increase the computed slope and reduce the computed intercept. Although this might be advantageous for prognostication in heart failure [80] and PAH [11], not only it underestimates ventilatory efficiency (equation 1) but it also does not accurately describe the underlying response profile. As mentioned, however, most patients with moderate-to-severe COPD are unable to exercise beyond the RCP. In other words, there is no upward inflection in the $V^{\prime} \mathrm{E}$ versus $V^{\prime} \mathrm{CO}_{2}$ response in most of these patients. Thus, in practice, drawing a single line from unloaded to peak exercise fits well the overall $V^{\prime} \mathrm{E}$ response in this particular sub-group of patients [29].

Some studies have examined the influence of potential modifiers on ventilatory efficiency. Ageing has been consistently associated with higher $V \mathrm{D} / V \mathrm{~T}$ and poorer ventilatory efficiency, regardless the method of expression (ratio or slope) [74, 79, 81] or level of fitness [82]. Females typically present with slightly greater $V^{\prime} \mathrm{E}-V^{\prime} \mathrm{CO}_{2}$ slopes than males [79], likely a consequence of a lower $V \mathrm{~T}$ [83]. The fact that $\mathrm{PaCO}_{2}$ does not differ between younger versus elderly or men versus women $[1,73]$ provides another piece of evidence that exercise $V^{\prime} \mathrm{E}$ increases precisely to maintain a stable alveolar ventilation $/ V^{\prime} \mathrm{CO}_{2}$ ratio $[1,2,4,73]$. It is also remarkable that exercise modality (walking versus cycling) does not seem to influence ventilatory efficiency in normal subjects $[74,81]$ though the $V^{\prime} \mathrm{E}-V^{\prime} \mathrm{CO}_{2}$ slope was higher during treadmill walking compared with cycling in moderate-to-severe COPD [13].

\section{Ventilatory efficiency and exercise intolerance}

A substantial body of evidence has accumulated indicating that abnormalities in ventilatory efficiency across the continuum of disease severity in COPD (table 1). Poor ventilatory efficiency has been found to be a key 
physiological abnormality in symptomatic patients with largely preserved forced expiratory volume in $1 \mathrm{~s}$ (FEV1) (figure S4) [29, 21, 26, 28, 30, 33]. The physiological basis for these derangements seems to stem from an enlarged $V \mathrm{D}$ per se rather than a small $V \mathrm{~T}$ or a low $\mathrm{PaCO}_{2}$ [30]. In fact, external (series) VD predictably increased $V^{\prime} \mathrm{E} / V^{\prime} \mathrm{CO}_{2}$ in these patients [21]. Additional research is warranted to investigate the structural correlates of increased $V D$ in mild COPD, e.g. microvascular disease [84], early emphysema [32, 85, 86], ventilation distribution heterogeneity $[27,86]$. Regardless of the mechanism(s), high $V^{\prime} \mathrm{E} / V^{\prime} \mathrm{CO}_{2}$ nadir is linked to earlier attainment of critical dynamic mechanical constraints: inspiratory reserve volume becomes critically reduced. This explains, in part, the increased exertional dyspnoea and reduced exercise capacity in mild COPD compared with age-matched healthy controls [21, 23, 26, 28, 30, 45]. This pattern of abnormalities was also seen in most patients with moderate airflow obstruction (Global Initiative for Chronic Obstructive Lung Disease (GOLD) stage 2) [29]. Collectively, these studies point to the important contribution of reduced ventilatory efficiency to dyspnea and reduced exercise capacity in smokers with only mild-to-moderate airflow obstruction [87, 88]. Interestingly, $V^{\prime} \mathrm{E} / V^{\prime} \mathrm{CO}_{2}$ nadir was also increased in symptomatic [16], but not in asymptomatic [33], smokers without COPD. These findings are consistent with the notion that poor ventilatory efficiency is instrumental to explain exertional dyspnoea at the earlier stages of the disease [87].

Similarly to heart failure [89-91], $V \mathrm{D} / V \mathrm{~T}$ worsens as disease severity increases in patients with COPD [88]. Interestingly, however, while the most commonly used parameter of ventilatory efficiency in the clinical literature (the $V^{\prime} \mathrm{E}-V^{\prime} \mathrm{CO}_{2}$ slope) increases from mild to severe heart failure $[4-7,10]$, the $V^{\prime} \mathrm{E}-V^{\prime} \mathrm{CO}_{2}$ slope decreases and the $V^{\prime} \mathrm{E}$ intercept increases in severe-to-very-severe COPD compared with milder disease. Consequently, the $V^{\prime} \mathrm{E} / V^{\prime} \mathrm{CO}_{2}$ nadir may remain stable (but still higher than in health) if the effects of a low
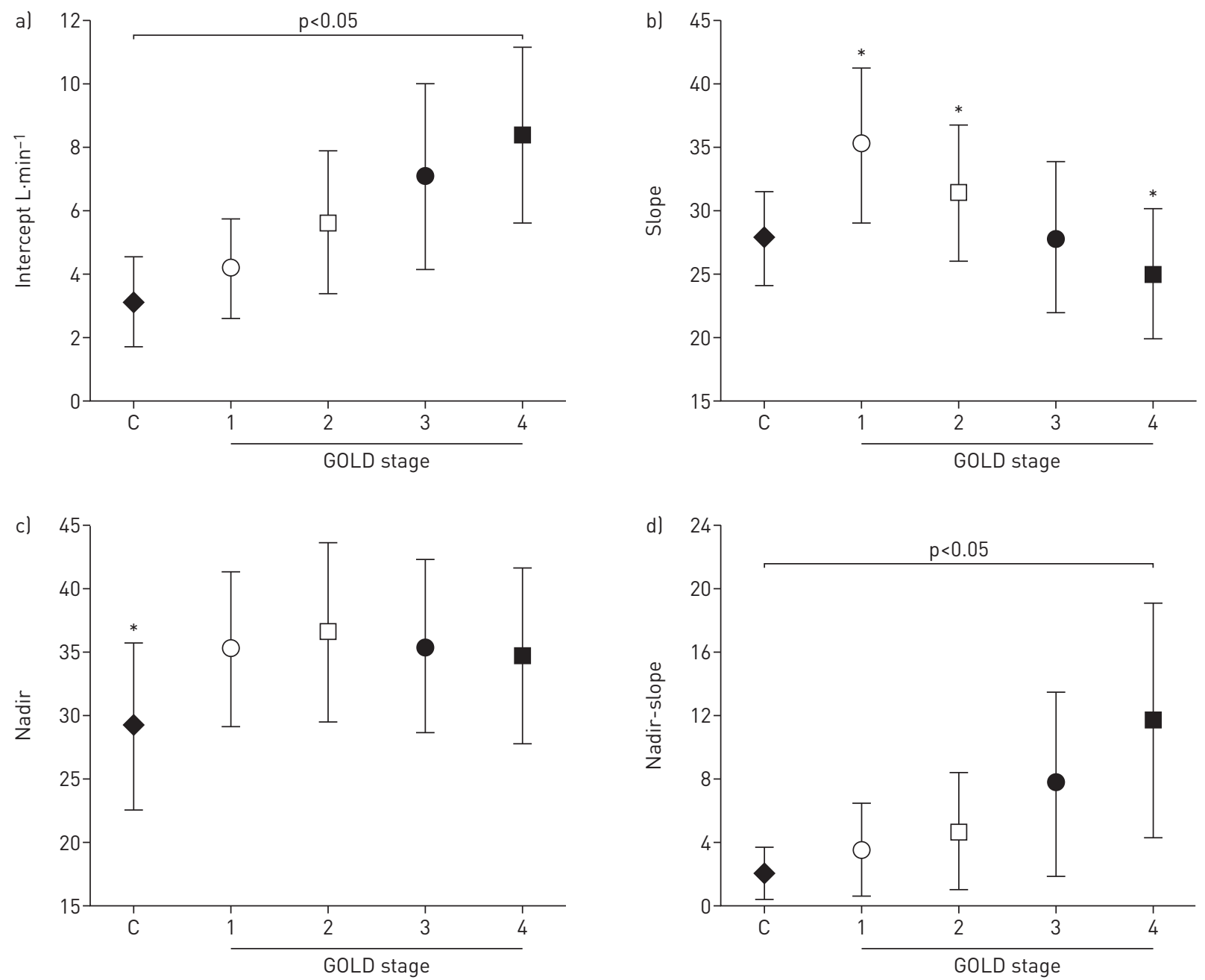

FIGURE 2 Effects of chronic obstructive pulmonary disease (COPD) severity on different parameters of ventilatory efficiency. Ventilation ( $V$ 'E)-carbon dioxide output $\left(V^{\prime} \mathrm{CO}_{2}\right)$ intercept increased (a) and $V^{\prime} \mathrm{E}-V^{\prime} \mathrm{CO}_{2}$ slope diminished (b) as the disease progressed from Global Initiative for Chronic Obstructive Lung Disease (GOLD) stages 1 to 4 . As the $V^{\prime} E / V^{\prime} \mathrm{CO}_{2}$ nadir depends on both slope and intercept, it remained elevated (compared with controls (C)) across disease stages (c). Increasing nadir-slope differences from GOLD stages 1 to 4 reflects the impact of a progressively higher intercept (d). Reproduced from [29] with permission from the publisher. 
slope in the nadir are cancelled out by a high intercept or even diminished if the slope is markedly reduced in severe-to-very-severe COPD (figure 2 and figure S3 for representative patients) [29]. The seemingly paradoxical finding of lower $V^{\prime} \mathrm{E}-V^{\prime} \mathrm{CO}_{2}$ slope in advanced $\mathrm{COPD}$ is likely explained by worsening mechanical constraints to $V^{\prime} \mathrm{E}$ increase [88] and, in end-stage disease, to hypercapnia (see section Physiological bases) $[14,92]$. Increases in $V^{\prime} \mathrm{E}$ intercept in COPD were associated with worsening dynamic hyperinflation, greater exertional dyspnoea and poorer exercise tolerance as the disease evolved [29]. Interestingly, obesity in COPD also decreased $V^{\prime} \mathrm{E} / V^{\prime} \mathrm{CO}_{2}$ nadir, likely due to greater ventilatory constraints and, conceivably, a higher $\mathrm{PaCO}_{2}$ set-point [17].

Little is known about the structural correlates of the $V^{\prime} \mathrm{E}-V^{\prime} \mathrm{CO}_{2}$ slope and the $V^{\prime} \mathrm{E}$ intercept in COPD. Adding external $V D$ in normal subjects had a more discernible effect on the $V^{\prime} \mathrm{E}$ intercept than the $V^{\prime} \mathrm{E}-$ $V^{\prime} \mathrm{CO}_{2}$ slope both in health $[68,93,94]$ and mild COPD [21]. However, in-series VD may not perfectly mimic alveolar (in-parallel) $V D$ as found in patients with pulmonary diseases. Thus, the former is associated with a greater $\mathrm{CO}_{2}$ loading in the airways (re-breathing), which might further challenge ventilatory control $[71,72]$. It could be argued that as the $V^{\prime} \mathrm{E}-V^{\prime} \mathrm{CO}_{2}$ slope is reduced by progressive mechanical respiratory constraints in severe-to-very-severe COPD [29], a high $V^{\prime} \mathrm{E}$ intercept is a necessary and empirical consequence of a shallower slope independent of the $V_{D}$ [92]. Nevertheless, some patients with COPD do present with shallow slopes but high intercepts and vice versa $[29,43]$. Additional studies examining changes in $V^{\prime} \mathrm{E}-V^{\prime} \mathrm{CO}_{2}$ slope and $V^{\prime} \mathrm{E}$ intercept across the continuum of COPD severity in the context of structural abnormalities (emphysema severity, pulmonary microvascular abnormalities, small airway disease) and $\mathrm{CO}_{2}$ chemosensitivity might shed new light on the topic (table 2).

\section{Impact of co-morbidities on ventilatory efficiency}

Poor ventilatory efficiency has been consistently reported in PAH $[11,12]$, heart failure $[4-7,10]$ and, to a lesser extent, coronary artery disease [95]. This is likely secondary to a complex interaction among increased ventilatory drive from multiple afferent sources (chemo-, baro- and ergoreception) and high $V \mathrm{D} / V_{\mathrm{T}}$ [96]. Impaired ventilatory efficiency persists in $\mathrm{COPD}$ with associated $\mathrm{PAH}[36,37]$ with the highest $V^{\prime} \mathrm{E}-V^{\prime} \mathrm{CO}_{2}$ slope found in severe, out-of-proportion pulmonary hypertension [38]. Interestingly, the $V^{\prime} \mathrm{E}-V^{\prime} \mathrm{CO}_{2}$ slope did not differ in severe to very severe COPD regardless if they had coexistent PAH or not [40]. These findings support the notion that severe respiratory mechanical constraints in COPD dampen an excessive ventilatory response despite potential increases in "wasted" ventilation and other sources of afferent stimuli [29].

Joint analysis of three independent investigations [41, 43, 44] indicates that patients with COPD-heart failure overlap present with higher $V^{\prime} \mathrm{E}-V^{\prime} \mathrm{CO}_{2}$ slopes but lower $V^{\prime} \mathrm{E}$ intercepts than patients with $\mathrm{COPD}$ alone (figure S5). Moreover, overlap patients had greater $V^{\prime} \mathrm{E}$ intercepts compared with heart failure in isolation [43]. Thus,

TABLE 2 Key unanswered clinical questions on exercise ventilatory efficiency in chronic obstructive pulmonary disease (COPD)

\section{Exercise intolerance}

Influence of co-morbidities

Risk assessment/prognosis

Effects of interventions
What are the structural determinants of increased dead space in mild disease?

What is the physiological meaning of the $V^{\prime} E-V^{\prime} \mathrm{CO}_{2}$ intercept?

Is ventilatory efficiency consistently associated with specific disease phenotypes?

How does very severe, end-stage disease impact on ventilatory efficiency?

Is resting $V^{\prime} \mathrm{E}-V^{\prime} \mathrm{CO}_{2}$ clinically useful to predict exercise intolerance and dyspnea?

Do emphysema extent and COPD phenotype influence ventilatory efficiency in COPD- heart failure overlap?

Do heart failure etiology and heart failure with preserved ejection fraction influence ventilatory efficiency in overlap?

Does oscillatory exercise ventilation impact on dyspnea and exercise intolerance in overlap?

What is the effect of exertional hypoxia on ventilatory efficiency in hypoxemic overlap?

Does ventilatory efficiency relate to right ventricular-pulmonary arterial coupling in COPD?

Why does ventilatory efficiency predict poor peri-operative outcome in lung resection surgery?

What is the best parameter of ventilatory efficiency to predict poor surgical outcome across the spectrum of disease severity?

Does poor ventilatory efficiency independently predict poor outcome in severe to very severe patients?

How best associate ventilatory efficiency with clinical data to determine prognosis?

Does longitudinal assessment of ventilatory efficiency improve prognosis estimation?

Do exercise training and inspiratory muscle training improve ventilatory efficiency?

What is the most sensitive parameter to detect improvement in ventilatory efficiency?

Do interventions aimed to improve pulmonary vascular function impact on ventilatory efficiency?

Is there any beneficial effect on pharmacological interventions in overlap and out-of-proportion pulmonary hypertension?

Do bronchodilators improve ventilatory efficiency in selected patients?

$V^{\prime}$ E: ventilation; $V^{\prime} \mathrm{CO}_{2}$ : carbon dioxide output. 
though heart failure further worsened ventilatory efficiency in COPD, lung mechanical constraints (and increased $\mathrm{CO}_{2}$ "set-point" in more advanced COPD) blunted the overall ventilatory response compared with heart failure alone. Importantly, impaired ventilatory efficiency in COPD-heart failure overlap was associated with greater exertional dyspnoea and poorer exercise tolerance [44]. There is also recent evidence that periodic breathing, which is associated with increased $V D$ and poor ventilatory efficiency [96], increases dyspnoea and reduces exercise tolerance in these patients [45]. Of note, the ventilatory oscillations were associated with higher operating lung volumes; moreover, they consistently ceased when critical inspiratory constraints were reached (figure S4) [45]. This observation highlights the overriding influence of abnormal mechanics in constraining exercise ventilation in COPD, even in the presence of a heightened ventilatory drive.

It remains unclear whether emphysema extent, disease phenotype, heart failure aetiology and heart failure with preserved ejection fraction [97] influence ventilatory efficiency in individual COPD-heart failure overlap patients. For instance, coronary artery disease, even without overt heart failure, also increased ventilatory inefficiency in COPD [42]. Arterial hypoxemia leading to high hypoxic drive does not seem to contribute to poor ventilatory efficiency in overlap [44]; however, few hypoxaemic patients were enrolled in previous studies $[41,43,44]$. Although $\beta$-blockers failed to decrease the $V^{\prime} \mathrm{E} / V^{\prime} \mathrm{CO}_{2}$ nadir in COPD [39], the impact of prospective pharmacological interventions on ventilatory efficiency remains unknown in COPD-heart failure overlap and in COPD patients with out-of-proportion pulmonary hypertension. Potential improvements in ventilatory efficiency might prove valuable to decrease exertional dyspnoea and improve exercise tolerance in selected patients, particularly when cardiocirculatory abnormalities predominate over mechanical constraints (table 2) [38].

\section{Risk assessment and prognosis}

Most patients submitted to lung resection surgery due to lung cancer present with COPD [98]. Resting pulmonary function tests and, to a lesser extent, peak $\mathrm{O}_{2}$ uptake $\left(V^{\prime} \mathrm{O}_{2}\right)$ [99] have been used to assess perioperative risk in these patients. There is mounting evidence that a high $V^{\prime} \mathrm{E}-V^{\prime} \mathrm{CO}_{2}$ slope is also a powerful predictor of poor surgical outcome for lung resection surgery [46-48], likely superior to peak $V^{\prime} \mathrm{O}_{2}$ [48]. In this context, a high $V^{\prime} \mathrm{E}-V^{\prime} \mathrm{CO}_{2}$ slope might indicate greater $V \mathrm{D}$ due to more extensive emphysema and/or high pulmonary vascular pressures, poorer cardiac performance, higher sympathetic drive, worse exertional hypoxemia and greater ergorreceptor stimulation [100]. Of note, however, few patients with severe to very severe COPD (who usually present with lower $V^{\prime} \mathrm{E}-V^{\prime} \mathrm{CO}_{2}$ slopes) (figure 2) undergo extensive lung resection surgery and/or pre-operative CPET [46-48]. Thus, it remains to be investigated whether a low $V^{\prime} \mathrm{E}-V^{\prime} \mathrm{CO}_{2}$ slope predicts poor outcome in selected patients who despite severe to very severe airflow obstruction are potential candidates for resection, e.g. young patients with limited disease and no major co-morbidities.

Poor ventilatory efficiency (increased $V^{\prime} \mathrm{E}-V^{\prime} \mathrm{CO}_{2}$ slope or $V^{\prime} \mathrm{E} / V^{\prime} \mathrm{CO}_{2}$ nadir) has a powerful negative association with survival in heart failure independent of peak $V^{\prime} \mathrm{O}_{2}[4-7,10]$. A recent study extended these observations to patients with COPD, regardless the presence of coexistent heart failure. Moreover, only resting lung hyperinflation added value to $V^{\prime} \mathrm{E} / V^{\prime} \mathrm{CO}_{2}$ nadir as a prognosticator [49]. Interestingly, a high $V^{\prime} \mathrm{E} / V^{\prime} \mathrm{CO}_{2}$ nadir predicted mortality due to respiratory and non-respiratory causes, suggesting that the above-mentioned abnormal cardiorespiratory mechanisms may also underlie increased risk of earlier mortality (figure 3) [49]. A small prospective investigation found that a high $V^{\prime} \mathrm{E} / V^{\prime} \mathrm{CO}_{2}$ nadir added to impaired resting right ventricular systolic function in predicting poor outcome in COPD-heart failure overlap [50]. If these findings are confirmed in larger multicentre studies, ventilatory efficiency might become an important effort-independent prognostic parameter in patients with COPD with or without heart failure as co-morbidity (table 2).

\section{Effects of interventions}

The effects of interventions on ventilatory efficiency have been helpful to uncover the underlying mechanisms of exercise intolerance and dyspnoea in COPD while providing a physiological rationale for their main mechanism of action. For instance, interventions primarily aimed at releasing the mechanical constraints (heliox [55, 59, 60, 65], lobectomy [58], and bronchodilators $[54,56,64]$ ) increased $V^{\prime} \mathrm{E}$ at a given $V^{\prime} \mathrm{CO}_{2}$. These findings fit well with the concept that an increased slope of the $V^{\prime} \mathrm{E}-V^{\prime} \mathrm{CO}_{2}$ relationship should not be uniformly interpreted as indicative of poor ventilatory efficiency in advanced COPD, at least from a "quantitative" perspective. Nevertheless, these interventions also reduced the operating lung volumes and exertional breathlessness; thus, it could be argued that ventilation became "qualitatively" and subjectively more efficient [88].

A different scenario emerged in response to another group of interventions which decreased $V^{\prime} \mathrm{E}$ at a given $V^{\prime} \mathrm{CO}_{2}$. Thus, single- [51] and double-lung [61] transplantation and lung volume reduction surgery [63, 66] lessened $V \mathrm{D}$ and increased $V \mathrm{~T}$ thereby reducing $V \mathrm{D} / V \mathrm{~T}$ with consequent benefits to ventilatory efficiency. This suggests that the marked effects of these interventions on $V \mathrm{D} / V_{\mathrm{T}}$ (which would lessen $V^{\prime} \mathrm{E}$ ) relatively outweighed the consequences of lower mechanical constraints, which would otherwise increase $V^{\prime} \mathrm{E}$ [39, 46-49, 98-100]. Lower neural drive (e.g. supplemental $\mathrm{O}_{2}$ [59], spinal anaesthesia [62]) also diminished $V^{\prime} \mathrm{E}$ at a given 
a)

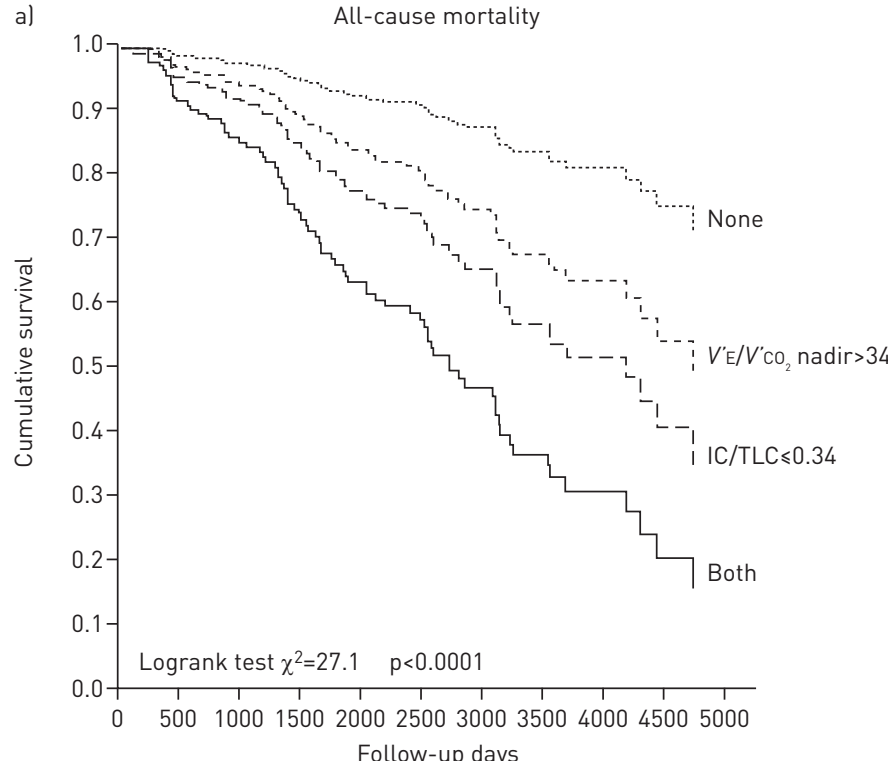

$V^{\prime} \mathrm{E} / V^{\prime} \mathrm{CO}_{2}$ nadir

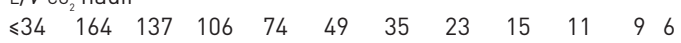

$\begin{array}{llllllllllll}>34 & 124 & 108 & 90 & 72 & 56 & 39 & 23 & 11 & 8 & 6 & 4\end{array}$

$\mathrm{IC} / \mathrm{TLC}$

$\begin{array}{llllllllllll}>0.34 & 156 & 129 & 96 & 67 & 44 & 28 & 13 & 9 & 7 & 5 & 4\end{array}$

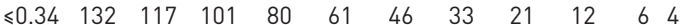

$V^{\prime}$ E $/ V^{\prime} \mathrm{CO}_{2}$ nadir and IC/TLC

$\begin{array}{llllllllllll}\text { None } & 113 & 93 & 69 & 47 & 29 & 18 & 12 & 8 & 6 & 4 & 2\end{array}$

$\begin{array}{llllllllllll}\text { Both } & 81 & 73 & 64 & 53 & 40 & 28 & 19 & 10 & 4 & 4 & 2\end{array}$ b)

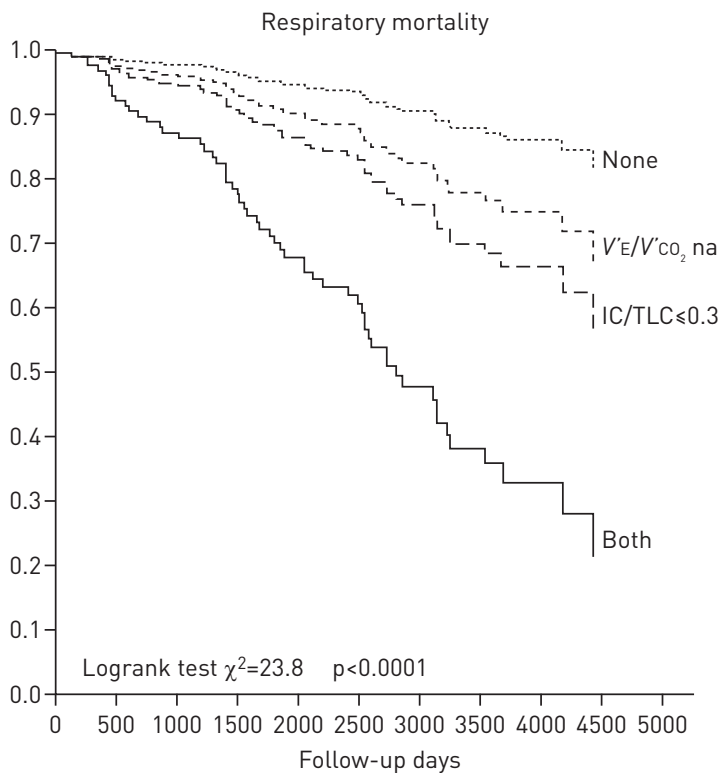

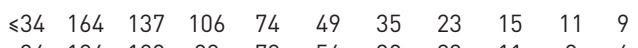

$\begin{array}{lllllllllll}>34 & 124 & 108 & 90 & 72 & 56 & 39 & 23 & 11 & 8 & 6\end{array}$

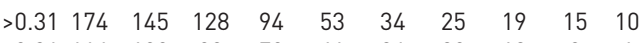

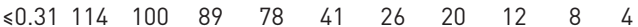

$\begin{array}{llllllllll}\text { None } 110 & 94 & 79 & 48 & 26 & 16 & 11 & 9 & 6 & 4\end{array}$

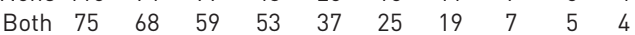

FIGURE 3 Value of poor ventilatory efficiency (high ventilation $\left(V^{\prime} \mathrm{E}\right) /$ carbon dioxide output $\left(V^{\prime} \mathrm{CO}_{2}\right)$ nadir) in isolation and associated with resting lung hyperinflation (low inspiratory/total lung capacity ratio (IC/TLC)) to predict all cause and respiratory mortality in patients with mild-to-severe COPD. Reproduced from [49] with permission from the publisher.

$V^{\prime} \mathrm{CO}_{2}$. Interestingly, some investigations found proportional decrements in $V^{\prime} \mathrm{E}$ and $V^{\prime} \mathrm{CO}_{2}$ with $\mathrm{O}_{2}$ supplementation $[52,53]$. This suggests that lower chemoreceptor drive to breathe is not the only mechanism underlying reduction in $V^{\prime} E$ during hyperoxia in COPD. Limited evidence also suggests that $V^{\prime} E$ tends to decrease in tandem with $V^{\prime} \mathrm{CO}_{2}$ after exercise training in COPD [57]. This is somewhat surprising considering the potential beneficial effects on breathing pattern (high $V \mathrm{~T}$ leading to a low $V \mathrm{D} / V \mathrm{~T}$ ) and peripheral muscle afferent stimuli [101]. Additional studies are warranted to further investigate the consequences of training on ventilatory efficiency, including the potential beneficial effects of inspiratory muscle training [102].

These considerations raise the question of why inhaled bronchodilators have not consistently changed the $V^{\prime} \mathrm{E}-V^{\prime} \mathrm{CO}_{2}$ relationship in COPD [103]. However, it should be recognised that ventilatory efficiency has not been specifically investigated in bronchodilator trials. Since high-intensity, constant work rate exercise testing is more sensitive than incremental CPET for the purpose of bronchodilator evaluation [104, 105], there are only sparse data on effects of bronchodilators on $V^{\prime} \mathrm{E}-V^{\prime} \mathrm{CO}_{2}$ slope and $V^{\prime} \mathrm{E}$ intercept during incremental tests. For instance, less mechanical constraints tending to increase $V^{\prime} \mathrm{E}[39,46-49,98-100]$ may be off-set by a lower $V \mathrm{D} / V \mathrm{~T}$, which tends to decrease $V^{\prime} \mathrm{E}[50,55,59,60]$. Such complex interactions would probably vary among subjects in large clinical trials. This topic also merits more detail analysis as inter-individual changes in ventilatory efficiency may explain the reported variability on exercise tolerance and dyspnoea despite apparent beneficial effects on resting lung mechanics in recent trials (table 2) [103]. For example, in mild COPD, effective bronchodilation and lung deflation may not translate into improved dyspnoea and exercise endurance if decreased ventilatory efficiency (and consequent increased inspiratory neural drive) remain unchanged $[16,106]$.

\section{Applying ventilatory efficiency to clinical management of COPD}

Based on the evidence summarised in table 1, there are some specific scenarios in which the $V^{\prime} \mathrm{E}-V^{\prime} \mathrm{CO}_{2}$ measurement can be useful to address clinically relevant issues in patients with COPD. Firstly, most symptomatic patients with preserved or only mildly reduced FEV1 are chronically sedentary [30]. Establishing an association between excess exercise ventilation and greater dyspnoea scores would provide evidence that patient's exercise intolerance is not a mere consequence of detraining $[9,16,87]$. This might prompt a more proactive approach to early treatment [107]. Secondly, some patients with COPD might present with 
“out-of-proportion" breathlessness (to FEV1 impairment) $[9,88]$. Poor ventilatory efficiency, often driving faster rates of dynamic hyperinflation [9, 16, 87], would provide a mechanistic explanation to patients' symptoms. This might indicate room for treatment optimisation, including pharmacological (e.g. dual bronchodilatation) [103] and non-pharmacological (e.g. pulmonary rehabilitation to decrease ventilatory demands) $[57,108]$. Thirdly, marked increases in $V^{\prime} \mathrm{E} / V^{\prime} \mathrm{CO}_{2}$ nadir should raise concerns regarding coexisting pulmonary hypertension [36, 39] or, in the right clinical context, heart failure [43, 44]. This is particularly true in the absence of another potential explanation for increased "wasted" ventilation, such as extensive emphysema on chest computed tomography [18]. Identification of co-morbidities increasing exercise ventilation and symptom burden is also important to avoid the potential iatrogenic consequences of excessive bronchodilator inhalation in patients with coexistent cardiovascular disease [109, 110]. Thus, further cardiological assessment might be warranted in these patients. Fourthly, a high $V^{\prime} \mathrm{E} / V^{\prime} \mathrm{CO}_{2}$ nadir in COPD patients with lung cancer should raise concerns regarding increased risk of peri-operative complications [46-48]. This might influence the decision in favour of a more economical resection in high-risk patients. Fifthly, identification of a high $V^{\prime} \mathrm{E} / V^{\prime} \mathrm{CO}_{2}$ nadir in a severely hyperinflated patient would indicate higher risk of a life-threatening exacerbation [49]. Thus, the patient would benefit from closer follow up and optimisation of anti-exacerbation measures (e.g. phosphodiesterase inhibitor, action plan, macrolide prophylaxis). Finally, documenting improved ventilatory efficiency after lung transplantation $[51,61]$ or lung volume reduction surgery $[63,66]$ would provide objective evidence of efficacy of these costly treatment approaches.

\section{Conclusions}

Compared with heart failure, for which the determinants and clinical consequences of an abnormal exercise $V^{\prime} \mathrm{E}-V^{\prime} \mathrm{CO}_{2}$ relationship have been well established, the value of ventilatory efficiency measurement during exercise has only recently become a target for systematic scrutiny in COPD (table 1). As in heart failure, the $V^{\prime} \mathrm{E}-V^{\prime} \mathrm{CO}_{2}$ slope and the $V^{\prime} \mathrm{E} / V^{\prime} \mathrm{CO}_{2}$ nadir are consistently increased in patients with mild to moderate COPD likely exposing unsuspected but clinically significant ventilation/perfusion abnormalities within the lungs. Conversely, while these specific efficiency parameters continue to worsen as heart failure progresses, this is not necessarily the case with advancing COPD due to increasing ventilatory constraints. Thus, a seemingly "normal" $V^{\prime} \mathrm{E}-V^{\prime} \mathrm{CO}_{2}$ slope does not rule out abnormal ventilatory efficiency in more advanced COPD. Higher $V^{\prime} \mathrm{E}$ intercept as COPD worsens, however, may result in a progressively higher $V^{\prime} \mathrm{E} / V^{\prime} \mathrm{CO}_{2}$ nadir. In fact, the contribution of a high $V^{\prime} \mathrm{E}$ intercept to $V^{\prime} \mathrm{E} / V^{\prime} \mathrm{CO}_{2}$ nadir increases as $\mathrm{COPD}$ evolves (as detailed in the supplementary material). Thus, the $V^{\prime} \mathrm{E}$ intercept might add important information to the interpretation of ventilatory (in)efficiency in patients with severe to very severe COPD.

Although much remains to be discovered, there is growing evidence that measurement of exercise ventilatory efficiency has potential clinical utility across the spectrum of disease severity in COPD. The $V^{\prime} \mathrm{E} / V^{\prime} \mathrm{CO}_{2}$ nadir seems a particularly useful index of ventilatory efficiency across the continuum of disease severity, being linked to important clinical outcomes such as dyspnoea, reduced exercise capacity and even mortality (table 1). Based on recent studies, ventilatory efficiency measurements may be important for the individualised assessment of exercise intolerance in mild-to-moderate COPD, notably in individuals with disproportionate dyspnoea (table 1).

\section{References}

Forster HV, Haouzi P, Dempsey JA. Control of breathing during exercise. Compr Physiol 2012; 2: 743-777.

Whipp BJ, Ward SA, Wasserman K. Ventilatory responses to exercise and their control in man. Am Rev Respir Dis 1984; 129: S17-S20.

3 Forster HV, Pan LG. Breathing during exercise: demands, regulation, limitations. Adv Exp Med Biol 1988; 227: 257-276.

4 Task Force ERS, Palange P, Ward SA, et al. Recommendations on the use of exercise testing in clinical practice. Eur Respir J 2007; 29: 185-209.

5 Cahalin LP, Chase P, Arena R, et al. A meta-analysis of the prognostic significance of cardiopulmonary exercise testing in patients with heart failure. Heart Fail Rev 2013; 18: 79-94.

6 Corrà U, Piepoli MF, Adamopoulos S, et al. Cardiopulmonary exercise testing in systolic heart failure in 2014: the evolving prognostic role: a position paper from the committee on exercise physiology and training of the heart failure association of the ESC. Eur J Heart Fail 2014; 16: 929-941.

7 Malhotra R, Bakken K, D'Elia E, et al. Cardiopulmonary exercise testing in heart failure. JACC Heart Fail 2016; 4: 607-616.

8 Neder JA, Jones PW, Nery LE, et al. Determinants of the exercise endurance capacity in patients with chronic obstructive pulmonary disease. The power-duration relationship. Am J Respir Crit Care Med 2000; 162: 497-504.

9 O'Donnell DE, Elbehairy AF, Faisal A, et al. Exertional dyspnoea in COPD: the clinical utility of cardiopulmonary exercise testing. Eur Respir Rev 2016; 25: 333-347.

10 Sue DY. Excess ventilation during exercise and prognosis in chronic heart failure. Am J Respir Crit Care Med 2011; 183: 1302-1310.

11 Ferreira EVM, Ota-Arakaki JS, Ramos RP, et al. Optimizing the evaluation of excess exercise ventilation for prognosis assessment in pulmonary arterial hypertension. Eur J Prev Cardiol 2014; 21: 1409-1419. 
Neder JA, Ramos RP, Ota-Arakaki JS, et al. Exercise intolerance in pulmonary arterial hypertension. The role of cardiopulmonary exercise testing. Ann Am Thorac Soc 2015; 12: 604-612.

Palange P, Forte S, Onorati P, et al. Ventilatory and metabolic adaptations to walking and cycling in patients with COPD. J Appl Physiol (1985) 2000; 88: 1715-1720.

O'Donnell DE, D'Arsigny C, Fitzpatrick M, et al. Exercise hypercapnia in advanced chronic obstructive pulmonary disease: the role of lung hyperinflation. Am J Respir Crit Care Med 2002; 166: 663-668.

Nakamoto FP, Neder JA, Maia J, et al. Skeletal muscle ergoreflex overactivity is not related to exercise ventilatory inefficiency in non-hypoxaemic patients with COPD. Eur J Appl Physiol 2007; 101: 705-712.

Ofir D, Laveneziana P, Webb KA, et al. Mechanisms of dyspnea during cycle exercise in symptomatic patients with GOLD stage I chronic obstructive pulmonary disease. Am J Respir Crit Care Med 2008; 177: 622-629.

Ora J, Laveneziana P, Ofir D, et al. Combined effects of obesity and chronic obstructive pulmonary disease on dyspnea and exercise tolerance. Am J Respir Crit Care Med 2009; 180: 964-971.

Paoletti P, De Filippis F, Fraioli F, et al. Cardiopulmonary exercise testing (CPET) in pulmonary emphysema. Respir Physiol Neurobiol 2011; 179: 167-173.

Guenette JA, Jensen D, Webb KA, et al. Sex differences in exertional dyspnea in patients with mild COPD: physiological mechanisms. Respir Physiol Neurobiol 2011; 177: 218-227.

Caviedes IR, Delgado I, Soto R. Ventilatory inefficiency as a limiting factor for exercise in patients with COPD. Respir Care 2012; 57: 583-589.

Chin RC, Guenette JA, Cheng S, et al. Does the respiratory system limit exercise in mild chronic obstructive pulmonary disease? Am J Respir Crit Care Med 2013; 187: 1315-1323.

Teopompi E, Tzani P, Aiello M, et al. Excess ventilation and ventilatory constraints during exercise in patients with chronic obstructive pulmonary disease. Respir Physiol Neurobiol 2014; 197: 9-14.

Guenette JA, Chin RC, Cheng S, et al. Mechanisms of exercise intolerance in global initiative for chronic obstructive lung disease grade 1 COPD. Eur Respir J 2014; 44: 1177-1187.

Ciavaglia CE, Guenette JA, Ora J, et al. Does exercise test modality influence dyspnoea perception in obese patients with COPD? Eur Respir J. 2014; 43: 1621-1630.

Barron A, Dhutia N, Mayet J, et al. Test-retest repeatability of cardiopulmonary exercise test variables in patients with cardiac or respiratory disease. Eur J Prev Cardiol 2014; 21: 445-453.

O'Donnell DE, Maltais F, Porszasz J, et al. The continuum of physiological impairment during treadmill walking in patients with mild-to-moderate COPD: patient characterization phase of a randomized clinical trial. PloS One 2014; 9: e96574.

Neder JA, O’Donnell CDJ, Cory J, et al. Ventilation distribution heterogeneity at rest as a marker of exercise impairment in mild-to-advanced COPD. COPD 2015; 12: 249-256.

Elbehairy AF, Raghavan N, Cheng S, et al. Physiologic characterization of the chronic bronchitis phenotype in GOLD grade IB COPD. Chest 2015; 147: 1235-1245.

Neder JA, Arbex FF, Alencar MC, et al. Exercise ventilatory inefficiency in mild to end-stage COPD. Eur Respir J. 2015; 45: 377-387.

Elbehairy AF, Ciavaglia CE, Webb KA, et al. Pulmonary gas exchange abnormalities in mild chronic obstructive pulmonary disease. Implications for dyspnea and exercise intolerance. Am J Respir Crit Care Med 2015; 191: 1384-1394.

Faisal A, Alghamdi BJ, Ciavaglia CE, et al. Common mechanisms of dyspnea in chronic interstitial and obstructive lung disorders. Am J Respir Crit Care Med 2016; 193: 299-309.

Crisafulli E, Alfieri V, Silva M, et al. Relationships between emphysema and airways metrics at high-resolution computed tomography (HRCT) and ventilatory response to exercise in mild to moderate COPD patients. Respir Med 2016; 117: 207-214.

Elbehairy AF, Guenette JA, Faisal A, et al. Mechanisms of exertional dyspnoea in symptomatic smokers without COPD. Eur Respir J 2016; 48: 694-705.

Soumagne T, Laveneziana P, Veil-Picard M, et al. Asymptomatic subjects with airway obstruction have significant impairment at exercise. Thorax 2016; 71: 804-811.

Jones JH, Zelt JT, Hirai DM, et al. Emphysema on thoracic CT and exercise ventilatory inefficiency in mild-tomoderate COPD. COPD 2016; in press [DOI: 10.1080/15412555.2016.1253670].

Holverda S, Bogaard HJ, Groepenhoff $\mathrm{H}$, et al. Cardiopulmonary exercise test characteristics in patients with chronic obstructive pulmonary disease and associated pulmonary hypertension. Respir Int Rev Thorac Dis 2008; 76: 160-167. Vonbank K, Funk GC, Marzluf B, et al. Abnormal pulmonary arterial pressure limits exercise capacity in patients with COPD. Wien Klin Wochenschr 2008; 120: 749-755.

Boerrigter BG, Bogaard HJ, Trip P, et al. Ventilatory and cardiocirculatory exercise profiles in COPD: the role of pulmonary hypertension. Chest 2012; 142: 1166-1174.

Thirapatarapong W, Armstrong HF, Bartels MN. Exercise capacity and ventilatory response during exercise in COPD patients with and without $\beta$ blockade. Lung 2013; 191: 531-536.

Thirapatarapong W, Armstrong HF, Bartels MN. Comparing cardiopulmonary exercise testing in severe COPD patients with and without pulmonary hypertension. Heart Lung Circ 2014; 23: 833-840.

Teopompi E, Tzani P, Aiello M, et al. Ventilatory response to carbon dioxide output in subjects with congestive heart failure and in patients with COPD with comparable exercise capacity. Respir Care 2014; 59: 1034-1041.

Thirapatarapong W, Armstrong HF, Bartels MN. Comparison of cardiopulmonary exercise testing variables in COPD patients with and without coronary artery disease. Heart Lung J Crit Care 2014; 43: 146-151.

Apostolo A, Laveneziana $\mathrm{P}$, Palange $\mathrm{P}$, et al. Impact of chronic obstructive pulmonary disease on exercise ventilatory efficiency in heart failure. Int J Cardiol 2015; 189: 134-140.

Arbex FF, Alencar MC, Souza A, et al. Exercise ventilation in COPD: influence of systolic heart failure. COPD 2016; 13: 693-699.

Rocha A, Arbex FF, Alencar MCN, et al. Physiological and sensory consequences of exercise oscillatory ventilation in heart failure-COPD. Int J Cardiol. 2016; 224: 447-453.

Torchio R, Guglielmo M, Giardino R, et al. Exercise ventilatory inefficiency and mortality in patients with chronic obstructive pulmonary disease undergoing surgery for non-small-cell lung cancer. Eur J Cardiothorac Surg 2010; 38: 14-19. 

strongest predictor of respiratory complications and death after pulmonary resection. Ann Thorac Surg 2012; 93: 1802-1806

48 Shafiek H, Valera JL, Togores B, et al. Risk of postoperative complications in chronic obstructive lung diseases patients considered fit for lung cancer surgery: beyond oxygen consumption. Eur J Cardiothorac Surg 2016; 50: 772-779.

49 Neder JA, Alharbi A, Berton DC, et al. Exercise ventilatory inefficiency adds to lung function in predicting mortality in COPD. COPD 2016; 13: 416-424.

50 Alencar MC, Arbex F, O'Donnell DE, et al. Does exercise ventilatory inefficiency predict poor outcome in heart failure patients with COPD? J Cardiopulm Rehab Prev 2016; 36: 454-459.

51 Orens JB, Becker FS, Lynch JP, et al. Cardiopulmonary exercise testing following allogeneic lung transplantation for different underlying disease states. Chest 1995; 107: 144-149.

52 Somfay A, Porszasz J, Lee SM, et al. Dose-response effect of oxygen on hyperinflation and exercise endurance in nonhypoxaemic COPD patients. Eur Respir J 2001; 18: 77-84.

53 O'Donnell DE, D’Arsigny C, Webb KA. Effects of hyperoxia on ventilatory limitation during exercise in advanced chronic obstructive pulmonary disease. Am J Respir Crit Care Med 2001; 163: 892-898.

54 O'Donnell DE, Voduc N, Fitzpatrick M, et al. Effect of salmeterol on the ventilatory response to exercise in chronic obstructive pulmonary disease. Eur Respir J 2004; 24: 86-94.

55 Palange P, Valli G, Onorati P, et al. Effect of heliox on lung dynamic hyperinflation, dyspnea, and exercise endurance capacity in COPD patients. J Appl Physiol 2004; 97: 1637-1642.

56 O'Donnell DE, Flüge T, Gerken F, et al. Effects of tiotropium on lung hyperinflation, dyspnoea and exercise tolerance in COPD. Eur Respir J 2004; 23: 832-840.

57 Porszasz J, Emtner M, Goto S, et al. Exercise training decreases ventilatory requirements and exercise-induced hyperinflation at submaximal intensities in patients with COPD. Chest 2005; 128: 2025-2034.

58 Bobbio A, Chetta A, Carbognani P, et al. Changes in pulmonary function test and cardio-pulmonary exercise capacity in COPD patients after lobar pulmonary resection. Eur J Cardiothorac Surg 2005; 28: 754-758.

Eves ND, Petersen SR, Haykowsky MJ, et al. Helium-hyperoxia, exercise, and respiratory mechanics in chronic obstructive pulmonary disease. Am J Respir Crit Care Med 2006; 174: 763-771.

60 Chiappa GR, Queiroga F, Meda E, et al. Heliox improves oxygen delivery and utilization during dynamic exercise in patients with chronic obstructive pulmonary disease. Am J Respir Crit Care Med 2009; 179: 1004-1010.

61 Habedank D, Ewert R, Hummel M, et al. The effects of bilateral lung transplantation on ventilatory efficiency, oxygen uptake and the right heart: a two-yr follow-up. Clin Transplant 2011; 25: E38-E45.

62 Gagnon P, Bussières JS, Ribeiro F, et al. Influences of spinal anesthesia on exercise tolerance in patients with chronic obstructive pulmonary disease. Am J Respir Crit Care Med 2012; 186: 606-615.

63 Kim V, Kretschman DM, Sternberg AL, et al. Weight gain after lung reduction surgery is related to improved lung function and ventilatory efficiency. Am J Respir Crit Care Med 2012; 186: 1109-1116.

64 Guenette JA, Webb KA, O’Donnell DE. Effect of fluticasone/salmeterol combination on dyspnea and respiratory mechanics in mild-to-moderate COPD. Respir Med 2013; 107: 708-716.

65 Queiroga F, Nunes M, Meda E, et al. Exercise tolerance with helium-hyperoxia versus hyperoxia in hypoxaemic patients with COPD. Eur Respir J 2013; 42: 362-370.

66 Armstrong HF, Dussault NE, Thirapatarapong W, et al. Ventilatory efficiency before and after lung volume reduction surgery. Respir Care 2015; 60: 63-71.

67 Whipp B, Pardy R. Breathing during exercise. In: Macklem P, Mead J, eds. Handbook of Physiology. Respiratory (Pulmonary Mechanics). Washington, American Physiological Society, 1986; pp. 605-629.

68 Robertson HT. Dead space: the physiology of wasted ventilation. Eur Respir J 2015; 45: 1704-1716

69 Johnson BD, Weisman IM, Zeballos RJ, et al. Emerging concepts in the evaluation of ventilatory limitation during exercise: the exercise tidal flow-volume loop. Chest 1999; 116: 488-503.

70 Whipp BJ. Control of the exercise hyperpnea: the unanswered question. Adv Exp Med Biol 2008; 605: 16-21.

71 Poon C-S, Tin C. Mechanism of augmented exercise hyperpnea in chronic heart failure and dead space loading Respir Physiol Neurobiol. 2013; 186: 114-130.

72 Ward SA. Commentary on "Mechanism of augmented exercise hyperpnea in chronic heart failure and dead space loading” by Poon and Tin. Respir Physiol Neurobiol 2013; 189: 203-210. Dempsey JA, Smith CA. Pathophysiology of human ventilatory control. Eur Respir J 2014; 44: 495-512.

74 Sun X-G, Hansen JE, Garatachea N, et al. Ventilatory efficiency during exercise in healthy subjects. Am J Respir Crit Care Med 2002; 166: 1443-1448.

Ward SA. Ventilatory control in humans: constraints and limitations. Exp Physiol 2007; 92: 357-366. Whipp BJ, Ward SA. Cardiopulmonary coupling during exercise. J Exp Biol 1982; 100: 175-193.

Zacarias EC, Neder JA, Cendom SP, et al. Heart rate at the estimated lactate threshold in patients with chronic obstructive pulmonary disease: effects on the target intensity for dynamic exercise training. J Cardpulm Rehabil 2000; 20: 369-376.

78 Agostoni P, Corrà U, Cattadori G, et al. Prognostic value of indeterminable anaerobic threshold in heart failure Circ Heart Fail 2013; 6: 977-987.

79 Neder JA, Nery LE, Peres C, et al. Reference values for dynamic responses to incremental cycle ergometry in males and females aged 20 to 80. Am J Respir Crit Care Med 2001; 164: 1481-1486.

80 Myers J, Oliveira R, Dewey F, et al. Validation of a cardiopulmonary exercise test score in heart failure. Circ Heart Fail 2013; 6: 211-218

81 Habedank D, Reindl I, Vietzke G, et al. Ventilatory efficiency and exercise tolerance in 101 healthy volunteers. Eur J Appl Physiol 1998; 77: 421-426.

82 Faisal A, Webb KA, Guenette JA, et al. Effect of age-related ventilatory inefficiency on respiratory sensation during exercise. Respir Physiol Neurobiol 2015; 205: 129-139.

83 Neder JA, Dal Corso S, Malaguti C, et al. The pattern and timing of breathing during incremental exercise: a normative study. Eur Respir J. 2003; 21: 530-538.

84 Hueper K, Vogel-Claussen J, Parikh MA, et al. Pulmonary microvascular blood flow in mild chronic obstructive pulmonary disease and emphysema. The MESA COPD study. Am J Respir Crit Care Med 2015; 192: 570-580.

85 Boutou AK, Nair A, Douraghi-Zadeh D, et al. A combined pulmonary function and emphysema score prognostic index for staging in chronic obstructive pulmonary disease. PloS One 2014; 9: e111109. 
Barbera JA, Roca J, Ramirez J, et al. Gas exchange during exercise in mild chronic obstructive pulmonary disease. Correlation with lung structure. Am Rev Respir Dis 1991; 144: 520-525.

O'Donnell DE, Neder JA, Elbehairy AF. Physiological impairment in mild COPD. Respirol Carlton Vic 2016; 21: 211-223.

O'Donnell DE, Laveneziana $\mathrm{P}$, Webb $\mathrm{K}$, et al. Chronic obstructive pulmonary disease: clinical integrative physiology. Clin Chest Med 2014; 35: 51-69.

Woods PR, Olson TP, Frantz RP, et al. Causes of breathing inefficiency during exercise in heart failure. J Card Fail 2010; 16: 835-842.

Kee K, Stuart-Andrews C, Ellis MJ, et al. Increased dead space ventilation mediates reduced exercise capacity in systolic heart failure. Am J Respir Crit Care Med 2016; 193: 1292-1300.

Robertson HT. Gas exchange consequences of left heart failure. Compr Physiol 2011; 1: 621-634.

Poon C-S, Tin C, Song G. Submissive hypercapnia: Why COPD patients are more prone to $\mathrm{CO} 2$ retention than heart failure patients. Respir Physiol Neurobiol 2015; 216: 86-93.

Ward SA, Whipp BJ. Ventilatory control during exercise with increased external dead space. J Appl Physiol Respir Environ Exerc Physiol 1980; 48: 225-231.

Gargiulo P, Apostolo A, Perrone-Filardi P, et al. A non invasive estimate of dead space ventilation from exercise measurements. PloS One 2014; 9: e87395.

Belardinelli R, Lacalaprice F, Carle F, et al. Exercise-induced myocardial ischaemia detected by cardiopulmonary exercise testing. Eur Heart J 2003; 24: 1304-1313.

Agostoni P, Apostolo A, Albert RK. Mechanisms of periodic breathing during exercise in patients with chronic heart failure. Chest 2008; 133: 197-203.

Guazzi M, Myers J, Arena R. Cardiopulmonary exercise testing in the clinical and prognostic assessment of diastolic heart failure. J Am Coll Cardiol 2005; 46: 1883-1890.

Brunelli A, Charloux A, Bolliger CT, et al. The European Respiratory Society and European Society of Thoracic Surgeons clinical guidelines for evaluating fitness for radical treatment (surgery and chemoradiotherapy) in patients with lung cancer. Eur J Cardiothorac Surg 2009; 36: 181-184.

Brutsche MH, Spiliopoulos A, Bolliger CT, et al. Exercise capacity and extent of resection as predictors of surgical risk in lung cancer. Eur Respir J 2000; 15: 828-832.

Brunelli A. Ventilatory efficiency slope: an additional prognosticator after lung cancer surgery. Eur J Cardiothorac Surg 2016; 50: 780-781.

Louvaris Z, Vogiatzis I. Physiological basis of cardiopulmonary rehabilitation in patients with lung or heart disease. Breathe 2015; 11: 120-127.

Dall'Ago P, Chiappa GRS, Guths $\mathrm{H}$, et al Inspiratory muscle training in patients with heart failure and inspiratory muscle weakness: a randomized trial. J Am Coll Cardiol 2006; 47: 757-763.

advances and hopes for the future. Expert Rev Respir Med 2016; 10: 823-834.

Puente-Maestu L, Palange P, Casaburi R, et al. Use of exercise testing in the evaluation of interventional efficacy: an official ERS statement. Eur Respir J 2016; 47: 429-460.

Casaburi R. Factors determining constant work rate exercise tolerance in COPD and their role in dictating the minimal clinically important difference in response to interventions. COPD 2005; 2: 131-136.

Casaburi R, Maltais F, Porszasz J, et al. Effects of tiotropium on hyperinflation and treadmill exercise tolerance in mild to moderate chronic obstructive pulmonary disease. Ann Am Thorac Soc 2014; 11: 1351-1361.

Elbehairy AF, Webb KA, Neder JA, et al. Should mild COPD be treated? Evidence for early pharmacological intervention. Drugs 2013; 73: 1991-2001.

Wadell K, Webb KA, Preston ME, et al. Impact of pulmonary rehabilitation on the major dimensions of dyspnea in COPD. COPD 2013; 10: 425-435.

Güder G, Rutten FH. Comorbidity of heart failure and chronic obstructive pulmonary disease: more than coincidence. Curr Heart Fail Rep 2014; 11: 337-346.

Sundh J, Ekström M. Persistent disabling breathlessness in chronic obstructive pulmonary disease. Int J Chron Obstruct Pulmon Dis 2016; 11: 2805-2812. 